\title{
The Role of Macroeconomic Factors in Explaining the Cost of Capital: Evidence from a Group of Emerging Economies
}

\author{
Nicholas Apergis (Corresponding author) \\ Department of Banking \& Financial Management \\ University of Piraeus, 80 Karaoli \& Dimitriou, 18534 Piraeus, Greece \\ E-mail: napergis@unipi.gr \\ Sofia Eleftheriou \\ Department of Business Administration \\ University of Piraeus, 80 Karaoli \& Dimitriou, 18534 Piraeus, Greece \\ E-mail: sofelef@webmail.unipi.gr
}

Received: April 23, $2012 \quad$ Accepted: May 9, $2012 \quad$ Published: June 1, 2012

doi:10.5296/ajfa.v4i1.1694 URL: http://dx.doi.org/10.5296/ajfa.v4i1.1694

\begin{abstract}
This study analyzes the dynamic relationship between the cost of capital and macroeconomic factors for a group of emerging markets spanning the period 1996-2009 and using the GMM estimator methodology, suggested in Arellano and Bond (1991). The empirical findings indicate that these macroeconomic factors play a significant role in explaining the cost of capital in the emerging markets.
\end{abstract}

Keywords: Cost of capital, Macroeconomic factors, Emerging countries, Panel data, GMM methodology 


\section{Introduction and Literature}

\subsection{General Issues}

The cost of equity capital is considered as a crucial factor in assessing investment opportunities across international capital markets. The general approach is to use the capital asset pricing model (CAPM) to assess the cost of the equity capital. This general employment is based on the fact that once the future payoffs from capital market investments are risky, then the return employed to assess the net present value of such investments should be generated by a comparable risky alternative investment opportunity, such as investments in the stock market. In other words, the CAPM predicts that the expected return can be employed as a discount rate in assessing the net present value of a capital market investment.

In a globalized world characterized by increased capital mobility, valuation is highly important in emerging markets, especially for privatization, joint ventures, mergers and acquisitions and restructuring. However, the valuation issue turns to be more difficult in emerging markets due to higher risks, such as macroeconomic volatility, capital controls, political and regulatory changes, enforced contract and investor rights and corruption. Macroeconomic volatility, which is the main theme of our study, seems to be extremely important for emerging markets, where the financial collapse and subsequent recession have generated increased nonperforming bank loans. At the same time, there is no general consensus among academics and practitioners as to the best approach to use in estimating the cost of capital with regard to firms operating in emerging markets. These markets are considered to be less integrated on a regional and/or world level, and the approach adopted to evaluate the cost of capital may affect local market volatility. (Graham and Harvey, 2001) argue that the cost of capital in emerging markets also receives a downward adjustment due to diversification effects. A potential reason for this is that the higher, vis-à-vis the developed markets, systematic risk for these economies should be added and reflected in the cost of capital. Finally, the risks associated with emerging markets are by majority considered as extra premia added to the discount factor (the cost of capital) used to calculate the present value of future cash flows, a procedure used extensively by firms to evaluate the potential profitability of future investment projects.

However, certain studies document the invalidation of a simple association between risk and return, as the CAPM predicts (Lakonishok and Shapiro, 1986). Moreover, Fama and French (1993) denote that more factors than firm's fundamentals and market risk could be responsible for determining a firm's financial aggregates, such as stock returns. Swanson et al. (2001) indicate that firm's fundamental signals provide value relevant information about the effects of certain macroeconomic variables on the market's expectation about changes in future cash flows and stock prices. Al-Qenae et al. (2002) investigate the effect of earnings and certain macroeconomic variables on stock prices for the Kuwait stock market. Their findings show that there exists a significant relationship between stock prices and earnings as well as macroeconomic variables, such as inflation and interest rates. By contrast, Johnson et al. (2000) do not find any relation between stock prices in 25 emerging economies and the extent of certain macroeconomic variables. 
The absence of a simple association as it is predicted by the CAPM turns stronger for the case of emerging markets, which are less efficient and less liquid vis-à-vis the developed markets. Harvey (1995) shows that such markets are characterized by low betas, which make the evidence predicted by the CAPM less valid while the simple CAPM model should incorporate country risk ratings as an additional explanatory variable in determining expected returns. Within a different strand of the investigation Bekaert and Harvey (2000) and Sokalska (2001) argue that it is the local macroeconomic environment that seems to be more important in determining stock price movements.

\subsection{Macroeconomic Conditions and Capital Markets}

The Arbitrage Pricing Theory (APT), as it was introduced by Ross (1976), initiated the use of variables that are associated with the macroeconomic environment of the firm. Chen et al. (1986) express the equity returns as a function of macroeconomic variables within their 'Macroeconomic Factor Model'. They conclude that stock returns are affected by certain macroeconomic variables mainly through the variables of the discount rate and expected dividends. The majority of relevant studies investigate the association between financial aggregates and macroeconomic variables for the U.S. (Clare and Thomas, 1994; Gjerde and Saettem, 1999; Flannery and Protopapadakis, 2002). Other studies pursue a similar investigation for the economies of East Asia (Bailey and Chang, 1996; Ibrahim and Aziz, 2003), while a third group of studies investigate the issue for groups of countries. Within this part of the literature, Bilson et al. (2001) suggest that consumer prices and real economic activity are not capable of explaining stock returns in a group of emerging economies, while exchange rates and money supply can do the job. Moreover, Wongbangpo and Sharma (2002) investigate the relevance of the macroeconomic environment in explaining stock returns for five ASEAN economies, while Rapach (2002) argues that inflation does not seem to be a significant variable in explaining stock price movements. Their results display that stock prices are positively related to output growth, which seems to be the sole macroeconomic variables that seems to be important. Tsoukalas (2003) finds a strong relationship between stock prices and the macroeconomic environment of firms listed on the Cypriot stock market. Chaudhuri and Smiles (2004) provide empirical support about a strong long-run relationship between stock prices and real macroeconomic activity, as it is described by real income, real private consumption and real oil prices for the Australian stock market while Hammoudeh and Aleisa (2004) show that the primary determinants of stock prices are inflation and variables associated with public finance. In general, the findings of the majority of the above studies have generated mixed results, depending not only on the set of macroeconomic variables used, but also on the methodological approach followed.

The primary goal of this study is to explore the role of macroeconomic factors in explaining the cost of equity capital for a group of emerging countries. Such economies usually attract the international investor's interest, while they are usually characterized by capital markets that offer very high returns, associated, however, with very high volatility of returns. The novelty of the study is that it uses a sample of countries never examined before in the relevant literature while it makes use of the GMM estimator methodology, suggested in Arellano and Bond (1991). The results of our study are expected to contribute to enrich the present 
literature and add significant value to investors, market practitioners as well as regulators. In particular, portfolio managers and investors are expected to find results useful for determining the future behavior and performance of the firms' cost of capital, for identifying investment approaches, pursuing available investment opportunities, and reducing the likelihood of high value losses in the market. In addition, market regulators are expected to find the results useful in avoiding any unexpected catastrophes, controlling market strategies and assessing the degree to which the stock market may need to be reformed.

\section{Data and Methodological Approaches}

\subsection{Data}

The study makes use of quarterly data for a group of countries spanning the period 1990-2009. The data set includes stock market prices, proxied by the country's capital market index, while a number of manufacturing firms were used from each country along with their stock prices. Data was obtained from Bloomberg. The Appendix provides information about the countries used along with the number of firms from each country from which those stock prices were obtained. The data set also consists of macroeconomic factors. The macroeconomic variables set includes certain important macroeconomic factors, such as the production capacity of the economy as it is proxied by GDP (Y)-since the variable affects the value of firm's cash flows, the consumer price index $(\mathrm{P})$-since the variable directly affects the nominal value of cash flows, the liquidity in the economy as it is proxied by the M1 (M) definition of money supply, the effective exchange rate $(E)$, the short-term interest rate $(R)$, the trade deficit (TR), as it is defined by the difference between exports and imports as a percentage of the country's GDP and the government deficit (DEF), as a percentage of the country's GDP. Data on macroeconomic fundamentals was obtained from the IMF's International Financial Statistics (IFS) database. Only non-financial firms listed on stock exchanges are involved. The reason is that financial firms have, on average, higher leverage (Fama and French, 1995).

\subsection{Methodological Approach}

The focus of the empirical analysis is the impact of certain macroeconomic variables on excess stock returns. Our benchmark model planned to be tested in this study is an extension of the standard CAPM mode, expressed as:

$$
r_{i t}-r^{f}=b_{0}+b_{1}\left(r_{t}^{m}-r_{t}^{f}\right)+b_{2} \Delta r_{1 t}+b_{3} \Delta r_{2 t}+\ldots .+b_{k} \Delta r_{k t}+u_{i t}
$$

where $i=1, \ldots, N$ for each firm in the ith country in the panel, $t=1, \ldots, T$ refers to the time period, $r_{i t}$ is the variable of stock returns for the stock $i, r_{t}{ }_{t}$ is the risk-free rater, $r_{t}^{m}$ is the local index return, while the $r_{k t}$ denote factors, such as the macroeconomic variables. Finally, $\Delta$ denotes first differences and u's are random variables, i.e. white noises with $\mathrm{N}\left(0, \sigma^{2}\right)$. The parameter $b_{1}$ is expected to be positive. The model has been estimated using the GMM estimator, suggested by Arellano and Bond (1991), while only statistically significant lags are used in the estimation. 


\section{Empirical Results}

\subsection{Panel Unit Root Tests}

At the outset, the statistical properties of all the variables under investigation are examined by testing for the presence of unit roots. There are a variety of panel unit root tests, which include Maddala and Wu (1999), Hadri (2000), Levin et al. (LLC, 2002), Im et al. (IPS, 2003), and Carrion-i-Silvestre et al. (2005), among others. Consider the following autoregressive specification:

$$
y_{i t}=\rho_{i} y_{i t-1}+\delta_{i} X_{i t}+\varepsilon_{i t}
$$

where $i=1, \ldots, N$ for each firm in the panel; $t=1, \ldots, T$ refers to the time period; $X_{i t}$ represents the exogenous variables in the model, including fixed effects or individual time trend; $\rho_{i}$ are the autoregressive coefficients; and $\varepsilon_{i t}$ are the stationary error terms. If $\rho_{i}<1, y_{i t}$ is considered weakly trend stationary, whereas if $\rho_{i}=1$, then $y_{i t}$ contains a unit root. The Hadri (2000) and Levin et al. (2002) panel unit root tests assume that the error terms, $\varepsilon_{i t}$, are independently and normally distributed random variables for all $i^{\prime} s$ and $t^{\prime} s$ with mean zero and constant variance. This assumption implies that the coefficient of $y_{i t-1}$ is homogeneous across all cross-section units of the panel and individual processes are cross-sectionally independent. In the case of dynamic panel data models, the recognition of parameter heterogeneity is important to avoid potential biases, which could emerge due to an improper specification.

- In light of parameter heterogeneity, the IPS panel unit root test is utilized which allows for heterogeneous autoregressive coefficients. Such heterogeneity could occur due to the different economic conditions and stages of economic development in each country. Im et al. (2003) suggest averaging the augmented Dickey-Fuller (ADF) unit root tests, while allowing for different orders of serial correlation, $\varepsilon_{i t}=\sum_{j=1}^{p_{i}} \varphi_{i j} \varepsilon_{i t-j}+u_{i t}$. Substitution of this expression into (1) yields:

$$
y_{i t}=\rho_{i} y_{i t-1}+\sum_{j=1}^{p_{i}} \varphi_{i j} \varepsilon_{i t-j}+\delta_{i} X_{i t}+\varepsilon_{i t}
$$

where $p_{i}$ represents the number of lags in the ADF regression. The null hypothesis is that each series in the panel contains a unit root $\left(H_{0}: \rho_{i}=1 \forall_{i}\right)$. The alternative hypothesis is 
that at least one of the individual series in the panel is stationary $\left(H_{0}: \rho_{i}<1\right)$. Im et al. (2003) specify a $t$-bar statistic as the average of the individual ADF statistics as follows:

$$
t-b a r=\frac{1}{N} \sum_{i=1}^{N} t_{\rho_{i}}
$$

where $t_{\rho_{i}}$ is the individual t-statistic for testing $H_{0}: \rho_{i}=1 \forall_{i}$ from (2). The $t$-bar statistic is normally distributed under the null hypothesis, with the critical values for given values of $N$ and $T$ provided by $\operatorname{Im}$ et al. (2003).

- The LLC test allows heterogeneity of individual deterministic effects and heterogeneous serial correlation structure of the error terms assuming homogeneous first order autoregressive parameters. They also assume that both $\mathrm{N}$ and $\mathrm{T}$ tend to infinity but $\mathrm{T}$ increases at a faster rate, such that $\mathrm{N} / \mathrm{T} \rightarrow 0$. Thus, a procedure is developed that uses t-statistics of the estimator to evaluate the hypothesis that each individual time series contains a unit root against the alternative hypothesis that each time series is stationary. The test also makes use of the ADF regression methodology, with the ADF regression defined as:

$$
\Delta y_{i t}=\alpha_{i}+\gamma_{i} y_{i, t-1}+\sum_{j=1}^{p_{i}} b_{i j} \Delta y_{i, t-j}+\varepsilon_{i t}
$$

Moreover, the test implements a separate ADF regression for each country where the lag order is permitted to vary across individual countries. The appropriate lag order is chosen by allowing the maximum lag order and then uses the t-statistic for the coefficients of the lag terms to determine if a smaller lag order is preferred. Next, it runs two separate regressions, such as:

$$
\Delta y_{i t}=a_{i}+\sum_{j=1}^{p_{i}} b_{i j} \Delta y_{i, t-j}+e_{i t}
$$

and

$$
\mathrm{y}_{\mathrm{i}, \mathrm{t}-\mathrm{l}}=\mathrm{a}_{\mathrm{i}}+\sum_{\mathrm{j}=1}^{\mathrm{p}_{\mathrm{i}}} \mathrm{b}_{\mathrm{ij}} \Delta \mathrm{y}_{\mathrm{i}, \mathrm{t}-\mathrm{j}}+\mathrm{v}_{\mathrm{i}, \mathrm{t}-\mathrm{j}}
$$

and we save the residuals $\left(\mathrm{e}_{\mathrm{it}}\right.$ and $\left.\mathrm{v}_{\mathrm{i}, \mathrm{t}-\mathrm{j}}\right)$. We divide the saved residuals by the regression standard error of the regression for normalization purposes and, next, we run the regression:

$$
\mathrm{e}_{\mathrm{it}}=\rho \mathrm{v}_{\mathrm{i}, \mathrm{t}-\mathrm{j}}+\varepsilon_{\mathrm{it}}
$$

with the null hypothesis being $\mathrm{H}_{0}: \rho_{1}=\ldots=\rho_{\mathrm{n}}=\rho=0$ and the alternative hypothesis $\mathrm{H}_{1}: \gamma_{1}$ $=. .=\gamma_{\mathrm{n}}=\gamma<0$ for all $\mathrm{i}$. LLC show that the asymptotic properties of the regression estimators are a mixture of properties derived for stationary panel data and properties derived in unit roots testing. This test seems to have certain limitations, such as that it depends seriously 
upon the independence assumption across individual regressions and hence not applicable if cross sectional correlation is present. In addition, a limitation is associated with the fact that the autoregressive parameters are considered identical across the panel regressions (see the above null hypothesis). However, this null hypothesis makes sense under some cases. As Maddala and $\mathrm{Wu}$ (1999) point out, the alternative hypothesis is too strong to be valid in any empirical case.

- Maddala and Wu (1999) offer a strategy that seems to overcome the limitations of both LLC and Im et al. tests. They suggest a non-parametric Fisher-type test, which is based on a combination of the $\mathrm{p}$-values of the t-statistics for a unit root in each cross-sectional unit (the ADF test). The testing approach has the advantage of allowing for as much heterogeneity across units as possible. Under the hypothesis that the test statistics are continuous, the significance of $\mathrm{p}$-values is independent in a uniform manner, e.g. they uniform $(0,1)$ variables and -2logp has a chi-squared distribution with two degrees of freedom. Using the additive property of the chi-squared variables, the statistic:

$\mathrm{N}$

$\lambda=-2 \sum \log \left(\mathrm{p}_{\mathrm{i}}\right)$ is constructed, which has a chi-squared distribution with $2 \mathrm{~N}$ degrees $\mathrm{i}=1$

of freedom. The advantage of this test is that it does not require an infinite number of groups to be valid, so we do not have to assume that all groups must have the same type of non-stochastic components. In addition, $\mathrm{T}$ is not necessarily assumed to be the same for all the cross-section units, its critical values are not sensitive to the choice of lag lengths in the ADF regressions, and finally, it does not have to assume that none of the groups have a unit root under the alternative hypothesis.

- The Hadri (2000) Lagrange Multiplier (LM) test is closely related to that of the Carrion-i-Silvestre et al. (2005) test. It has the advantage of combining both stationary and non-stationary variables and permits a formulation for a residual-based LM test of stationarity. Hadri adopts the following representation:

$$
\mathrm{y}_{\mathrm{it}}=\mathrm{z}_{\mathrm{it}}{ }^{\prime} \gamma+\mathrm{r}_{\mathrm{it}}+\varepsilon_{\mathrm{it}}
$$

where $z_{i t}$ is the deterministic component, $r_{i t}$ is a random walk process defined as $r_{i t}=r_{i, t-1}+u_{i t}$, with $\mathrm{u}_{\mathrm{it}} \rightarrow \mathrm{iid}\left(0, \sigma_{\mathrm{u}}{ }^{2}\right)$ and $\varepsilon_{\mathrm{it}}$ is a stationary process. The null hypothesis of trend stationarity corresponds to the hypothesis that the variance of the random walk is zero. The $y_{\text {it }}$ process from above can be written as $\mathrm{y}_{\mathrm{it}}=\mathrm{z}_{\mathrm{it}}{ }^{\prime} \gamma+\mathrm{e}_{\mathrm{it}}$, where:

$$
\mathrm{e}_{\mathrm{it}}=\underset{\mathrm{j}=1}{\mathrm{~T}} \mathrm{u}_{\mathrm{ij}}+\varepsilon_{\mathrm{it}}
$$

The residuals from the above regression $\left(\mathrm{e}_{\mathrm{it}}\right)$ are obtained. This time the statistic can be written as:

$$
\mathrm{LM}=1 / \mathrm{N}_{\mathrm{i}=1 \mathrm{t}=1}^{\mathrm{N}} \underset{\mathrm{it}}{\sum}\left(\mathrm{S}_{\mathrm{it}}{ }^{2} / \mathrm{T}^{2} / \sigma_{\varepsilon}{ }^{2}\right)
$$


where $\sigma_{\varepsilon}{ }^{2}$ is the consistent Newey and West (1987) estimate of the long-run variance of residuals, while $S_{i t}$ is defined as above. The LM statistic is consistent and has an asymptotic normal distribution as both $\mathrm{T}$ and $\mathrm{N} \rightarrow \infty$. The main advantage of this test is that the moments of the asymptotic distribution are exactly derived, while the disturbance terms can be heteroskedastic across i. Finally, it is also possible to allow for serial dependence substituting the assumption that the errors $\varepsilon_{\mathrm{it}}$ are i.i.d. normally distributed over $\mathrm{t}$ with the assumption that they satisfy the strong mixing regularity conditions of Phillips and Perron (1988). In this case we replace $\sigma_{\varepsilon}^{2}$ by the long-run variance, defined as:

$$
\sigma^{2}=1 / \mathrm{N}_{\mathrm{i}=1}^{\mathrm{N}} \operatorname{limT}_{\mathrm{T} \rightarrow \infty}^{-1}\left(\mathrm{~S}_{\mathrm{iT}}{ }^{2}\right)
$$

A consistent estimator of the above variance is obtained using again the estimators provided by Newey and West (1994).

The results in Table 1 point out that the hypothesis that all the macroeconomic variables under study contain a unit root, is accepted at the $1 \%$ significant level in all tests, suggesting that these variables are I(1). By contrast, excess returns for individual stocks as well as for market indexes are shown to be $\mathrm{I}(0)$ variables.

Table 1. Panel unit root tests

\begin{tabular}{lll}
\hline \multicolumn{2}{l}{ IPS Panel Unit Root Tests } & \\
\hline Variables & Without Trend & With Trend \\
$\mathrm{y}$ & $-2.11(3)$ & $-2.28(3)$ \\
$\Delta \mathrm{y}$ & $-5.30(1)^{*}$ & $-5.66(2)^{*}$ \\
$\mathrm{~m}$ & $-1.09(2)$ & $-1.36(2)$ \\
$\Delta \mathrm{m}$ & $-4.93(2)^{*}$ & $-5.18(2)^{*}$ \\
fdef & $-1.71(2)$ & $-1.94(2)$ \\
$\Delta \mathrm{fdef}$ & $-4.83(1)^{*}$ & $-4.97(1)^{*}$ \\
$\mathrm{p}$ & $-1.83(3)$ & $-1.94(3)$ \\
$\Delta \mathrm{p}$ & $-5.48(1)^{*}$ & $-5.82(1)^{*}$ \\
$\mathrm{def}$ & $-2.13(2)$ & $-2.34(2)$ \\
$\Delta$ def & $-5.21(1)^{*}$ & $-5.74(1)^{*}$ \\
$\mathrm{r}_{\mathrm{i}-\mathrm{r}}^{\mathrm{f}}$ & $-7.71(2)^{*}$ & $-7.84(2)^{*}$ \\
$\mathrm{r}_{\mathrm{t}}^{\mathrm{m}}-\mathrm{r}_{\mathrm{t}}^{\mathrm{f}}$ & $-6.58(2)^{*}$ & $-6.82(1)^{*}$ \\
\hline LLC Panel Unit Root Tests & \\
\hline Variables & With Trend & \\
$\mathrm{y}$ & -2.03 & \\
$\Delta \mathrm{y}$ & $-5.28^{*}$ & \\
$\mathrm{~m}$ & -1.14 & \\
$\Delta \mathrm{m}$ & $-4.84^{*}$ & \\
fdef & -1.55 & \\
\hline
\end{tabular}




\begin{tabular}{ll}
\hline$\Delta$ fdef & $-4.94^{*}$ \\
$\mathrm{p}$ & -1.62 \\
$\Delta \mathrm{p}$ & $-5.27^{*}$ \\
$\mathrm{def}$ & -2.19 \\
$\Delta$ def & $-5.38^{*}$ \\
$\mathrm{r}_{\mathrm{i}-\mathrm{r}^{\mathrm{f}}}$ & $-6.42^{*}$ \\
$\mathrm{r}_{\mathrm{t}}{ }^{\mathrm{m}}-\mathrm{r}_{\mathrm{t}}^{\mathrm{f}}$ & $-6.94^{\mathrm{f}}$
\end{tabular}

Handri (hom) Panel Unit Root Tests

\begin{tabular}{lc}
\hline Variables & With Trend \\
$\mathrm{y}$ & $22.03^{*}$ \\
$\Delta \mathrm{y}$ & 1.09 \\
$\mathrm{~m}$ & $15.24^{*}$ \\
$\Delta \mathrm{m}$ & 1.14 \\
fdef & $16.55^{*}$ \\
$\Delta$ fdef & 1.44 \\
$\mathrm{p}$ & $17.62^{*}$ \\
$\Delta \mathrm{p}$ & 1.18 \\
$\mathrm{def}$ & $22.19^{*}$ \\
$\Delta$ def & 1.34 \\
$\mathrm{r}_{\mathrm{i}}-\mathrm{r}^{\mathrm{f}}$ & 1.37 \\
$\mathrm{r}_{\mathrm{t}}^{\mathrm{m}}-\mathrm{r}_{\mathrm{t}}^{\mathrm{f}}$ & 1.23 \\
\hline Handri (het) Panel Unit Root Tests \\
\hline Variables & With Trend \\
$\mathrm{y}$ & $20.32^{*}$ \\
$\Delta \mathrm{y}$ & 1.14 \\
$\mathrm{~m}$ & $13.22^{*}$ \\
$\Delta \mathrm{m}$ & 1.07 \\
fdef & $12.73^{*}$ \\
$\Delta$ fdef & 1.39 \\
$\mathrm{p}$ & $14.02^{*}$ \\
$\Delta \mathrm{p}$ & 1.25 \\
def & $18.14^{*}$ \\
$\Delta$ def & 1.27 \\
$\mathrm{r}_{\mathrm{i}}-\mathrm{r}^{\mathrm{f}}$ & 1.41 \\
$\mathrm{r}_{\mathrm{t}}^{\mathrm{m}}-\mathrm{r}_{\mathrm{t}}^{\mathrm{f}}$ & 1.37 \\
$\mathrm{Fish}$ \\
\end{tabular}

Fisher-ADF

Variables

y 20.45

$\Delta \mathrm{y} \quad 104.46^{*}$ 
$\mathrm{m}$

17.83

$\Delta \mathrm{m} \quad 98.77^{*}$

fdef $\quad 18.51$

$\Delta$ fdef $\quad 92.34^{*}$

$\mathrm{p}$

$\Delta \mathrm{p}$

$112.52^{*}$

def

19.75

$\Delta$ def

$108.75^{*}$

$\mathrm{r}_{\mathrm{i}}-\mathrm{r}^{\mathrm{f}}$

$112.57 *$

$r_{t}^{m}-r_{t}^{f}$

$108.47^{*}$

\begin{tabular}{lc}
\hline Fisher-PP & \\
\hline Variables & \\
$\mathrm{y}$ & 24.58 \\
$\Delta \mathrm{y}$ & $117.17^{*}$ \\
$\mathrm{~m}$ & 19.72 \\
$\Delta \mathrm{m}$ & $99.93^{*}$ \\
$\mathrm{fdef}$ & 21.56 \\
$\Delta$ fdef & $97.88^{*}$ \\
$\mathrm{p}$ & 19.59 \\
$\Delta \mathrm{p}$ & $119.69^{*}$ \\
Def & 24.17 \\
$\Delta$ def & $129.82^{*}$ \\
$\mathrm{r}_{\mathrm{i}}-\mathrm{r}^{\mathrm{f}}$ & $116.55^{*}$ \\
$\mathrm{r}_{\mathrm{t}}{ }^{\mathrm{m}}-\mathrm{r}_{\mathrm{t}}^{\mathrm{f}}$ & $113.07^{*}$
\end{tabular}

Numbers in parentheses are the augmented lags included in the unit root test, while $\Delta$ denotes first differences. * denotes statistical significance at $1 \%$

\subsection{Dynamic Heterogeneity}

An issue that it is of major concern is the heterogeneity of the firms included in this data set. In particular, through time and across countries, the effect of accounting information on stock returns was investigated. In the statistical framework of this study we first test for heterogeneity and then by controlling for it through appropriate techniques (Holtz-Eakin, 1986; Holtz et al., 1985). The dynamic heterogeneity, i.e. variation of the intercept over countries and time, across a cross-section of the relevant variables can be investigated as follows: In the first step, an $\operatorname{ADF}(n)$ equation for each relationship in the panel is estimated; then, the hypothesis of whether regression parameters are equal across these equations is tested. Next, a similar test of parameter equality is performed by estimating a n-order autoregressive model for each of the relationships under investigation. Standard Chow-type F tests under the null of parameter equality across all relationships are also performed. Heterogeneity in cross-sectional parameters is indicated if the results reject the null hypothesis. Finally, homogeneity error 
variance across groups is also examined as another measure of dynamic heterogeneity. White's tests for group-wise heteroscedasticity are employed to serve this objective. The results of this procedure are reported in Table 2. The empirical findings indicate that the relationship under consideration is characterized by heterogeneity of dynamics and error variance across groups, supporting the employment of panel analysis.

Table 2. Tests of dynamic heterogeneity across groups

\begin{tabular}{llll}
\hline Specification & $\operatorname{ADF}(3)$ & $\operatorname{AR}(3)$ & White's Test \\
\hline $28.16^{*}$ & $38.92^{*}$ & $68.37^{*}$ \\
\hline
\end{tabular}

$\mathrm{ADF}(3)$ reports the parameter equality test (F-test) across all relationships in the panel. $\mathrm{AR}(3)$ displays the F-test of parameter equality conducted in a third-order autoregressive model of the relationships. White's test reports the White's test of equality of variances across the investigated relationships in the panel. $\Delta$ denotes first differences. $*$ denotes statistical significance at $1 \%$.

\subsection{GMM Results}

The results concerning the GMM estimations are summarized in Table 3. The GMM estimator, suggested by Arellano and Bond (1991), ensures both efficiency and consistency since all slope coefficients are estimated simultaneously. The Sargan test ensures the validity of instruments used. In our model the coefficients are shown to have the expected theoretical signs and they are statistically significant at the 1 percent significance level. The empirical findings seem to lead us to the following observations:

- The empirical evidence with respect to the impact of inflation on stock prices is inconclusive. In particular, Chen et al. (1986), Flannery and Protopapadakis (2002) and Wongbangpo and Sharma (2002) argue that inflation is negatively associated with stock returns. In the same framework, Maysami and Koh (2000) argue that higher inflation usually leads to upcoming tighter economic policies that are expected to have a negative impact on financial aggregates. By contrast, according to Clare and Thomas (1994) and Ibrahim and Aziz (2003), this association turns out to be positive, which is probably explained by the inadequacy of the hedging role of stocks against inflation. Our results indicate that inflation is a factor that has a positive impact on excess stock returns in our emerging economies sample.

Evidence in the literature displays that there is a positive association between output and stock returns (Park, 1997). This association is mainly due to the reaction of stock market participants to macroeconomic variables tight to higher (lower) output, such as high (low) employment, which in turn, are positively related to earnings and future business conditions. Hassapis and Kalyvitis (2002) also show that there exists a positive association between stock returns and future growth, which is probably due to the link between anticipated economic growth and the current price of capital. Our empirical findings confirm the above arguments by reporting a positive association between income and excess stock returns. 
Mukherjee and Naka (1995) and Cheung and Ng (1998) report a positive association between money supply and stock prices, on the grounds that money supply changes have a positive impact on real economic activities variables. Gan et al. (2006) also display that opportunity costs of holding cash rise with higher interest rates and the trade-off and the trade-off to holding other interest-bearing assets would lead to lower share prices. Our empirical findings are consistent with these arguments by reaching a positive relationship between excess stock returns and money supply.

In terms now of budget deficits, the relationship between stock prices and such deficits is important, because large deficits tend to undermine investor's confidence through the inability of firms to raise capital on favorable terms. At the same time, large budget deficits affect stock prices through their impact on inflation as well as through expected future taxes and rising interest rates. Bulmash and Trivoli (1991) find a positive association between those deficits and stock returns. Adrangi and Allender (1998) provide evidence that a negative association between stock returns and budget deficits in many countries is documented. The empirical results of this study reveal a positive association between government deficits and excess stock returns, implying that in emerging economies these deficits act as a boost-up mechanism for the economy, thus, leading to higher stock returns.

- The current literature on the link between stock prices and the trade account deficit is small. Very few authors discuss the association between stock price shocks and global imbalances, such as Fratzscher et al. (2007), Barnett and Straub (2008) and Fretzscher and Straub (2009). The literature generates mixed results across countries. In our case, the association turns out to be positive, probably indicating that the presence of a trade deficit is expected to depreciate the domestic currency, thus, leading to higher exports and higher growth.

- The relationship between stock returns and interest rates is negative, a piece of evidence supported by Chen (1991), Gjerde and Saettem (1999) and Maysami and Koh (2000). This negative association implies that interest rates represent not only the opportunity cost of investments in the stock exchange market, but also the higher borrowing cost from the banking sector, considering that our economies under study belong in a bank-based borrowing system.

The constant terms turns out to be statistically insignificant, implying that by introducing the macroeconomic factors in the CAPM model keeps pricing errors very low.

Finally, the local indices are shown to be statistically insignificant, indicating that this factor as well is capable of explaining some of the volatility of stock returns. 
Table 3. GMM results

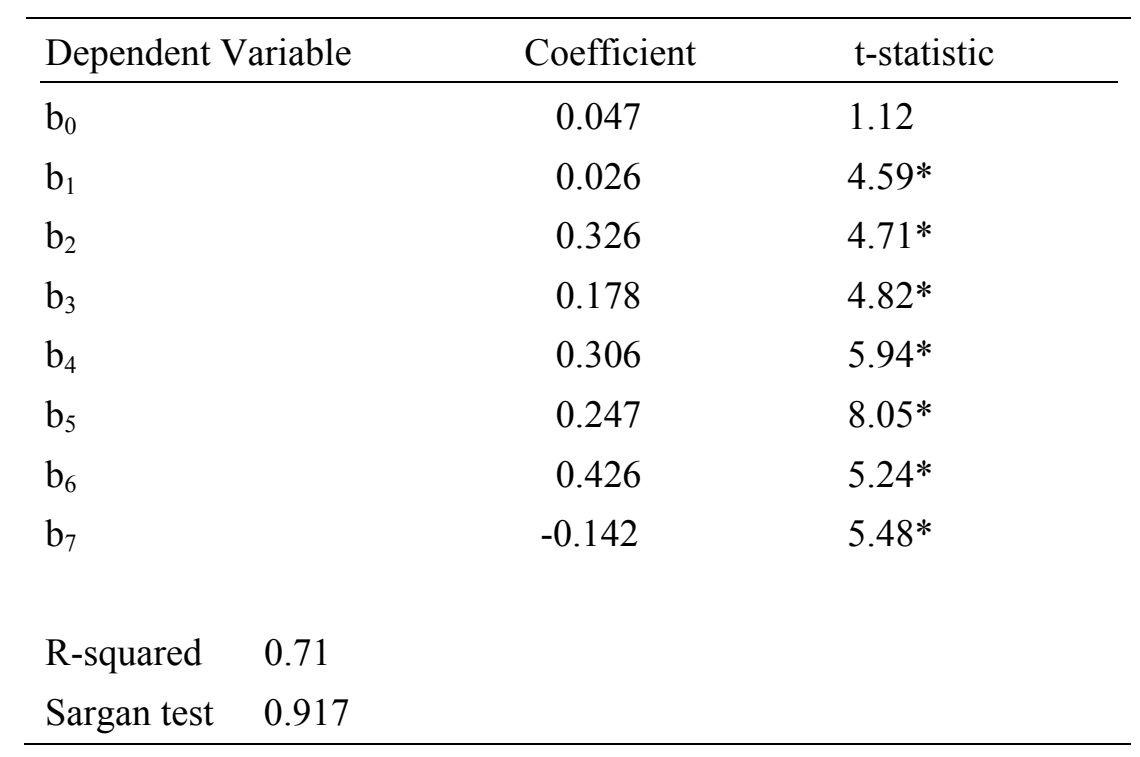

* denotes statistical significance at $1 \%$.

\section{Conclusions and Implications}

Our study investigated the relationship between excess stock returns and the macroeconomic environment for a sample of emerging economies. The empirical results recommend that potential investors should pay attention to information emerging from the macroeconomic environment. Our empirical findings have important implications for the association between the macroeconomic environment, the cost of capital and the capital budgeting process. In particular, the macroeconomic environment seems to be a crucial factor for capital budgeting. In calculating discount rates (the cost of capital) firms tend to incorporate the risks associated with macroeconomics to this discounting factor, an approach that will affect investment project strategic evaluation decisions. This also indicates that practitioners might not even apply the CAPM rule to evaluate their investments and to estimate their equity cost, implying that financial theory may have to reconsider and reevaluate the assumptions and implications of mainstream theories in capital budgeting and, thus, have to turn to alternative evaluation methods, such as the payback method.

In addition, the monetary authorities should also benefit from the empirical findings of this study, especially those that implement an inflation-targeting based monetary policy, considering the close tights of the stock market with the macroeconomic environment. A future research agenda could use an expanded set of macroeconomic variables, which might provide alternative information contents about their impact on stock returns.

\section{Acknowledgement}

The authors wish to thank two referees from the journal whose comments improved the quality of the paper. Needless to say, the usual disclaimer applies. 


\section{References}

Adrangi, B., \& Allender, M. (1998). Budget Deficits and Stock Prices: International Evidence. Journal of Economics and Finance, 22, 57-66. http://dx.doi.org/10.1007/BF02771476

Al-Qenae, R., Li, C., \& Wearing, B. (2002). The Information Content of Earnings on Stock Prices: The Kuwait Stock Exchange. Multinational Finance Journal, 6, 197-221.

Arellano, M., \& Bond, S. (1991). Some Tests of Specification for Panel Data: Monte Carlo Evidence and an Application to Employment Equations. Review of Economic Studies, 58, 277-297. http://dx.doi.org/10.2307/2297968

Bailey, W., \& Chung, Y. P. (1996). Risk and Return in the Philippine Equity Market: A Multifactor Exploration. Pacific-Basin Finance Journal, 4, 197-218. http://dx.doi.org/10.1016/0927-538X(96)00011-X

Barnett, A., \& Straub, R. (2008). What Drives U.S. Current Account Fluctuations? ECB Working Paper, No. 959. http://www.ecb.int/pub/pdf/scpwps/ecbwp959.pdf

Bekaert, G., \& Harvey, C. (2000). Foreign Speculators and Emerging Equity Markets. Journal of Finance, 55, 565-613. http://dx.doi.org/10.1111/0022-1082.00220

Bilson, C. M., Brailsford, T. J., \& Hooper, V. J. (2001). Selecting Macroeconomic Variables as Explanatory Factors of Emerging Stock market Returns. Pacific-Basin Finance Journal, 9, 401-426. http://dx.doi.org/10.1016/S0927-538X(01)00020-8

Bulmash, S., \& Trivoli, G. (1991). Time-Lagged Interactions Between Stock Prices and Selected Economic Variables. Journal of Portfolio Management, 17, 61-67. http://dx.doi.org/10.3905/jpm.1991.409351

Chaudhuri, K., \& Smiles, S. (2004). Stock Market and Aggregate Economic Activity: Evidence from Australia. Applied Financial Economics, 14, 121-129. http://dx.doi.org/10.1080/0960310042000176399

Chen, N. F. (1991). Financial Investment Opportunities and the Macroeconomy. Journal of Finance, 46, 529-554.

Chen, N. F., Roll, R., \& Ross, S. A. (1986). Economic Forces and the Stock Market. Journal of Business, 59, 383-403. http://dx.doi.org/10.1086/296344

Cheung, Y. W., \& Ng, L. K. (1998). International Evidence on the Stock Market and Aggregate Economic Activity. Journal of Empirical Finance, 5, 281-296. http://dx.doi.org/10.1016/S0927-5398(97)00025-X

Cjerde, O., Knivsfla, K. H., \& Soettem, F. (2005). The Value Relevance of Financial Reporting on the Oslo Stock Exchange over the Period 1964-2003. Working Paper, Norwegian School of Economics and Business Administration, Norway. http://papers.ssrn.com/sol3/papers.cfm?abstract_id=930390 
Clare, A. D., \& Thomas, S. H. (1994). Macroeconomic Factors, the APT and the UK Stock Market. Journal of Business Finance and Accounting, 21, 309-330. http://dx.doi.org/10.1111/j.1468-5957.1994.tb00322.x

Fama, E. F., \& French, K. R. (1993). Common Risk Factors in the Returns on Stocks and Bonds. Journal of Financial Economics, 33, 3-56. http://dx.doi.org/10.1016/0304-405X(93)90023-5

Fama, E. F., \& French, K. R. (1995). Size and Book-to-Market Factors in Earnings and Returns. Journal of Finance, 50, 131-155.

Flannery, M. J., \& Protopapadakis, A. A. (2002). Macroeconomic Factors do Influence Aggregate Stock Returns. Review of Financial Studies, 15, 751-782. http://dx.doi.org/10.1093/rfs/15.3.751

Fratzscher, M., \& Straub, R. (2009). Asset Prices and Current Account Fluctuations in G7 $\begin{array}{lllll}\text { Economies. } & \text { ECB } & \text { Working } & \text { Paper, } & \text { No. }\end{array}$ http://www.ecb.europa.eu/pub/pdf/scpwps/ecbwp1014.pdf

Fratzscher, M., Juvenal, L., \& Sarno, L. (2007). Asset Prices, Exchange Rates and the Current Account. ECB Working Paper, No. 790. http://www.ecb.europa.eu/pub/pdf/scpwps/ecbwp790.pdf

Gan, C., Lee, M., Young, H. W. A., \& Zhang, J. (2006). Macroeconomic Variables and Stock Market Interaction: New Zealand Evidence. Investment Management and Financial Innovations, 3, 5-20.

Gjerde, O., \& Saettem, F. (1999). Causal Relations Among Stock Returns and Macroeconomic Variables in a Small Open Economy. Journal of International Financial Markets, Institutions and Money, 9, 61-74. http://dx.doi.org/10.1016/S1042-4431(98)00036-5

Graham, J. R., \& Harvey, C. R. (2001). The Theory and Practice of Corporate Finance: Evidence from the Field. Journal of Financial Economics, 61, 1-29.

Hadri, K. (2000). Testing for Stationarity in Heterogeneous Panel Data. Econometric Journal, 3, 148-161. http://dx.doi.org/10.1111/1368-423X.00043

Hammoudeh, S., \& Aleisa, E. (2004). Dynamic Relationships among GCC Stock Markets and NYMEX Oil Future. Contemporary Economic Policy, 22, 250-269. http://dx.doi.org/10.1093/cep/byh018

Harvey, C. R. (1995). Predictable Risk and Returns in Emerging Markets. Review of Financial Studies, 8, 773-816. http://dx.doi.org/10.1093/rfs/8.3.773

Hassapis, C., \& Kalyvitis, S. (2002). Investigating the Links between Growth and Real Stock Price Changes with Empirical Evidence from the G-7 Economies. Quarterly Review of Economics and Finance, 42, 543-575. http://dx.doi.org/10.1016/S1062-9769(01)00111-9

Holtz-Eakin, D. (1986). Testing for Individual Effects in Dynamic Models Using Panel Data. NBER Technical Paper Series, No. 57. http://www.nber.org/papers/t0057.pdf 
Holtz-Eakin, D., W. Newey, \& H. Rosen (1985). Implementing Causality Tests with Panel.Data with an Example from Local Public Finance. NBER Technical Working Paper, No. 48. http://www.nber.org/papers/t0048.pdf

Im, K.S., M.H. Pesaran, \& Y. Shin (2003). Testing for Unit Roots in Heterogeneous Panels. Journal of Econometrics, 115, 53-74. http://dx.doi.org/10.1016/S0304-4076(03)00092-7

Johnson, S., Boone, P., Breach, A., \& Friedman, E. (2000). Corporate Governance in the Asian Financial Crisis. Journal of Financial Economics, 58, 141-186. http://dx.doi.org/10.1016/S0304-405X(00)00069-6

Lakonishok, J., \& Shapiro, A. (1986). Systematic Risk, Total Risk, and Size as Determinants of Stock Market Returns. Journal of Banking and Finance, 10, 115-132. http://dx.doi.org/10.1016/0378-4266(86)90023-3

Levin, R., Lin, C. F., \& Chu, C. (2002). Unit Root Tests in Panel Data: Asymptotic and Finite Sample Properties. Journal of Econometrics, 108, 1-24. http://dx.doi.org/10.1016/S0304-4076(01)00098-7

Maddala, G. S., \& Wu, S. (1999). A Comparative Study of Unit Root Tests with Panel Data and a New Simple Test. Oxford Bulleting of Economics and Statistics, 61, 631-652. http://dx.doi.org/10.1111/1468-0084.61.s1.13

Maysami, R. C., \& Koh, T. S. (2000). A Vector Error Correction Model of Singapore Stock Market. International Review of Economic and Finance, 9, 79-96. http://dx.doi.org/10.1016/S1059-0560(99)00042-8

Mukherjee, T. K., \& Naka, A. (1995). Dynamic Relations Between Macroeconomic Variables and the Japanese Stock Market: An Application of a Vector Error Correction Model. Journal of Financial Research, 18, 223-237.

Park, S. (1997). Rationality of Negative Stock-Price Responses to Strong Economic Activity. Financial Analysts Journal, 53, 52-56. http://dx.doi.org/10.2469/faj.v53.n5.2117

Rapach, D. E. (2002). The Long-Run Relationship Between Inflation and Real Stock Prices. Journal of Macroeconomics, 24, 331-351. http://dx.doi.org/10.1016/S0164-0704(02)00041-1

Ross, S. A. (1976). The Arbitrage Theory of Capital Asset Pricing. Journal of Economic Theory, 13, 341-360. http://dx.doi.org/10.1016/0022-0531(76)90046-6

Sokalska, M. (2001). What Drives Equity Returns in Central and Eastern Europe. Working Paper, Warsaw School of Economics. http://papers.ssrn.com/sol3/AbstractNotFound.cfm

Swanson, E., Rees, L., \& Juarez-Valdes, L. (2001). The Contribution of Fundamental Analysis in the Presence of Inflation and a Currency Devaluation. Working Paper, Texas A \& M University. http://papers.ssrn.com/sol3/papers.cfm?abstract_id=260596

Tsoukalas, D. (2003). Macroeconomic Factors and Stock Prices in the Emerging Cypriot Equity Market. Managerial Finance, $\quad$ 87-92. http://dx.doi.org/10.1108/03074350310768300 


\section{Macrothink}

Asian Journal of Finance \& Accounting ISSN 1946-052X

Wongbangpo, P., \& Sharma, S. C. (2002). Stock market and Macroeconomic Fundamental Dynamic Interactions: ASEAN-5 Countries. Journal of Asian Economics, 13, 27-51. http://dx.doi.org/10.1016/S1049-0078(01)00111-7

\section{Appendix}

\begin{tabular}{lc}
\hline Countries & Number of firms \\
Argentina & 175 \\
Brazil & 284 \\
Chile & 128 \\
Czech & 235 \\
Egypt & 42 \\
India & 570 \\
Indonesia & 355 \\
Israel & 140 \\
Malaysia & 367 \\
Mexico & 322 \\
Pakistan & 60 \\
Peru & 55 \\
Philippines & 110 \\
Thailand & 158 \\
South Africa & 140 \\
Venezuela & 85 \\
\hline
\end{tabular}

